\title{
Educação Inclusiva no Ensino Superior: Um Novo Desafio
}

Inclusive education at higher education: A new challenge

Marian A. L.

Dias Ferrari \& Marie

Claire Sekkel

Universidade

de São Paulo

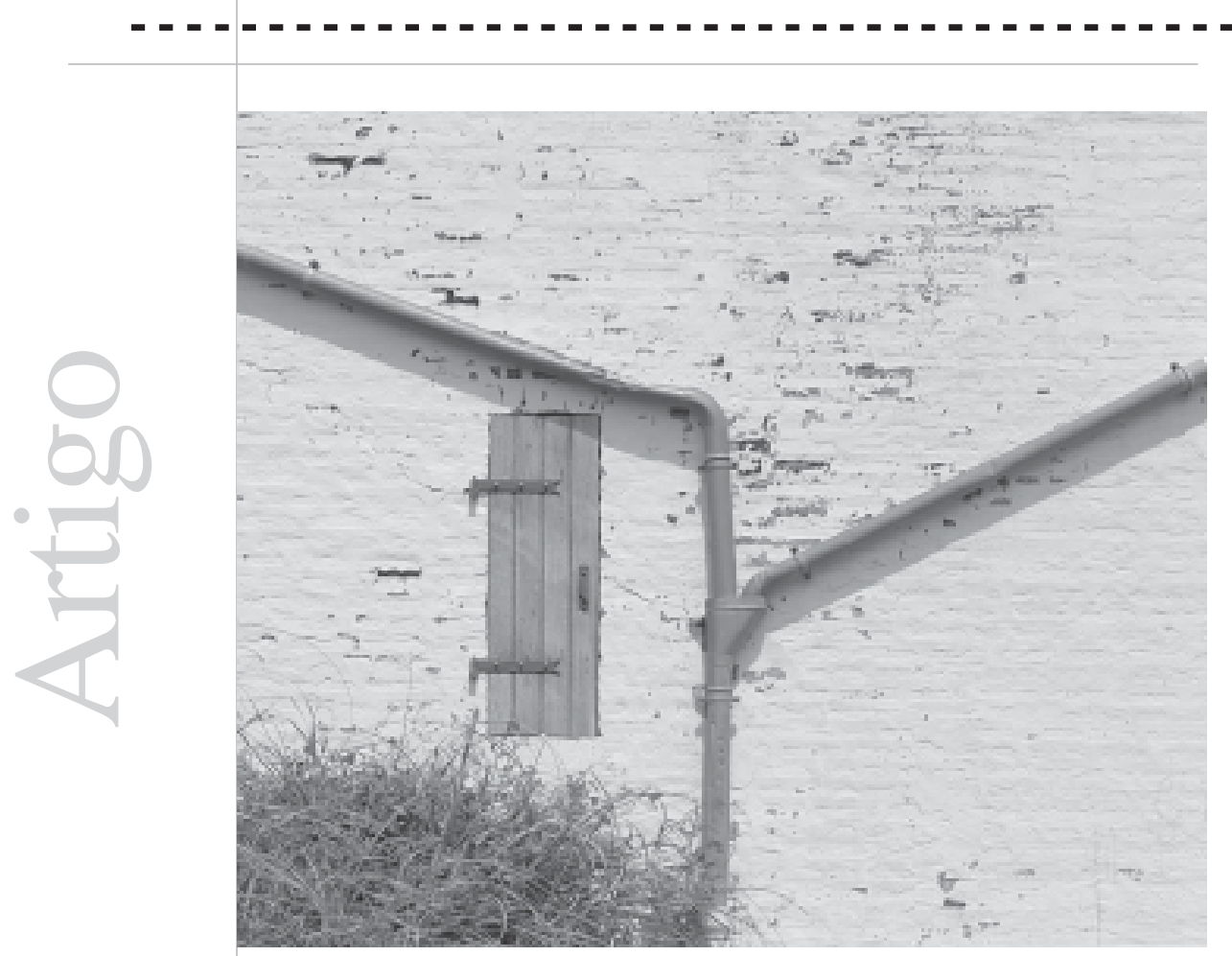




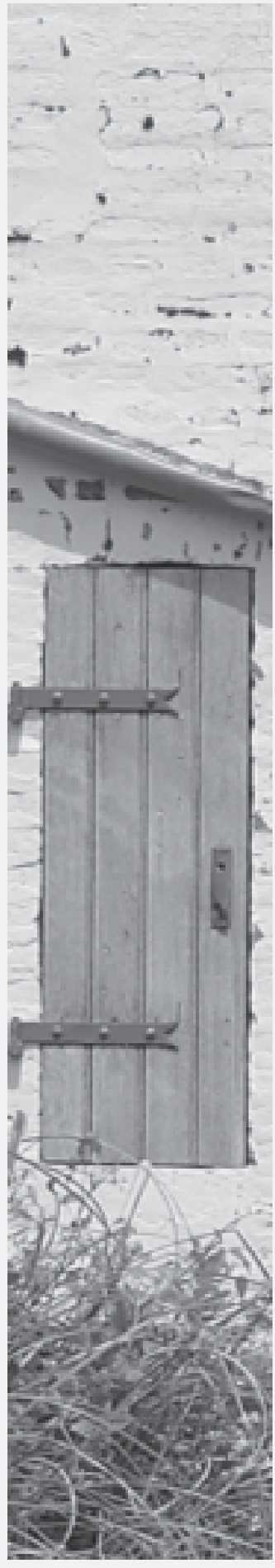

Resumo: O crescente ingresso de alunos com necessidades educacionais especiais na rede regular de ensino torna necessário um aprofundamento na reflexão sobre a educação inclusiva. Este artigo tem por objetivo discutir os desafios da educação inclusiva no ensino superior. Com essa finalidade, retomamos a história da Universidade, verificamos seus objetivos e características principais, suas determinações nas instituições de ensino superior brasileiras e analisamos o percurso da educação inclusiva no cenário mundial e nacional. A partir daí, levantamos questões específicas da educação inclusiva no ensino superior e identificamos três níveis de desafios a serem enfrentados: a tomada de posição das instituições sobre os objetivos e a elegibilidade dos alunos para seus cursos, a necessidade de formação pedagógica dos professores do ensino superior para a educação inclusiva e, por fim, uma prática educativa que propicie a participação de alunos e professores no reconhecimento das diferenças e na criação de estratégias para a superação das dificuldades que surgirem. Palavras-chave: educação inclusiva, deficiência intelectual, ensino superior, preconceito.

Abstract: The growing admission of students with intellectual disability in the regular classes at colleges and universities requires a deeper thought about inclusive education. This article aims to discuss the challenges that this new perspective provides in education, especially in the Brazilian higher education system, such as the purposes and the eligibility of their careers. The history of the University is briefly recovered and its main distinguishing marks, as well as its consequences at the Brazilian higher educational institutions. This article analyzes the inclusive education project at both national and international scenarios and identifies three levels of challenges in this field: the clearness of the institution's purposes and its degrees and who would be the ones eligible for those; the need of increasing our teacher's education so that they can be educated to take the differences into account and, at last, an openness to recognize and discuss the differences together with the students as well as create strategies to overwhelm all difficulties that may appear during the educational process.

Key- words: inclusive education, intellectual disabilities, higher education, prejudice. 
As lutas religiosas, provocadas pelos movimentos das reformas protestantes, trouxeramo controle das igrejas para dentro das universidades, o que tolheu a liberdade acadêmica.
Há pouco mais de uma década, as discussões sobre um modelo de educação inclusiva vêm ocupando lugar de destaque no cenário mundial. O desenvolvimento das práticas produz questões concretas nas instituições e exige respostas que não se encontram em manuais, livros ou diretrizes. A chegada dos alunos com necessidades educacionais especiais - NEE - e, entre eles, os alunos com deficiência intelectual no ensino superior, tem criado situações constrangedoras em sala de aula, que sequer chegaram às pautas das discussões institucionais. Os vestibulares não seletivos visam ao preenchimento das vagas oferecidas e abrem as portas das Instituições de Ensino Superior IES - que, ainda sem preparo, recebem alunos com os mais variados percursos escolares. Este artigo busca discutir os desafios ligados à entrada de alunos com necessidades educacionais especiais no ensino superior no atual cenário brasileiro.

A fim de buscar subsídios para essa discussão, retomaremos brevemente a história da Universidade - origem de todo o ensino superior - de modo a verificarmos seus objetivos e características principais bem como suas determinações nas instituições de ensino superior brasileiras. Em seguida, analisaremos o percurso da educação inclusiva no cenário mundial e nacional, e, para finalizar, levantaremos questões que explicitam a especificidade da educação inclusiva no ensino superior e os desafios por elas suscitados.

\section{Histórico sobre as universidades}

As diversas concepções de Universidade foram construídas historicamente, a fim de dar suporte às transformações sociais de cada momento e de cada cultura em que se inseriram. No Brasil, temos a influência de três modelos: francês, alemão e norte-americano (Durham, 2005). O modelo francês tem origem na criação da Universidade de Paris, no século XII, que surgiu a partir da congregação de professores autônomos numa corporação de ofícios (forma medieval de organização), na busca de um espaço de atuação com maior autonomia, diferentemente das escolas dos mosteiros e catedrais. A autonomia universitária tem origem nesse momento histórico.

"Era este o tipo de autonomia que os professores desejavam, e é basicamente a mesma que marcou toda sua história posterior. Isto é, exercer, fora da Igreja, o ofício de ensinar, o direito a admitir aprendizes, de formar novos mestres, fornecendo diplomas reconhecidos. Trata-se, de fato, do que hoje chamamos de liberdade acadêmica (Durham, 2005, p.6)”

As lutas religiosas, provocadas pelos movimentos das reformas protestantes, trouxeram o controle das igrejas para dentro das universidades, o que tolheu a liberdade acadêmica. Somente no século XIX, com a vitória das ideologias liberais, a liberdade acadêmica foi de novo valorizada. Surge então o modelo de universidade laico-estatal. Esse modelo, cujo paradigma se origina na Universidade de Berlim, traz um forte componente hierárquico, no qual o poder é concentrado na figura do catedrático. É ele quem exerce a liberdade acadêmica, que não se estende a todo o corpo docente. No modelo alemão, a forma de administração é rigidamente estabelecida; docentes e pessoal administrativo são funcionários públicos, e o currículo é estabelecido pelo governo. O sistema educacional é dual, e, finalizada a escola primária, os alunos se dividem em dois grupos: os que vão para o Gymnasium, que antecede a Universidade, cuja formação é exigente em termos humanísticos e científicos, e os que vão para a escola vocacional, voltada para o mercado de trabalho.

Na tradição alemã, a dualidade se estende ao ensino superior. Toda a formação profissional ou aplicada (inclusive as engenharias, a formação de professores primários, escolas agrícolas, de Odontologia e de administração), com exceção de Medicina e Direito, se fazem em institutos especiais. Dessa forma, a Universidade (e a elite 
que ela produz) está voltada quase que exclusivamente para as humanidades e as ciências básicas (Durham, 2005).

Cabe notar que tanto o modelo francês quanto o alemão organizam esse tipo de ensino de modo a que ele seja destinado a poucos alunos. Assim, a liberdade e a autonomia universitárias se restringem apenas ao grupo de catedráticos, que, por sua vez, ensinam a um seleto grupo de alunos que, terminados os estudos, constituirão essa mesma elite acadêmica. A Universidade é concebida como lugar para a formação de elites intelectuais, voltada para a produção de saber intelectual, e não profissional. O modelo de cátedras esteve presente nas universidades brasileiras até a reforma de 1968. O modelo dual chegou a ser institucionalizado no Brasil, mas vingou apenas no ensino secundário, e até hoje o ensino superior vocacional não é valorizado entre nós.

Já o modelo norte-americano influenciou as reformas universitárias em quase todos os países nas décadas de 60 e 70, e tem, como objetivo, ampliar o acesso ao ensino superior, sendo o que melhor resolveu o desafio do ensino de massa. É esse o modelo que atualmente lidera na pesquisa mundial, adotado por muitas entre as melhores universidades do mundo. Trata-se de um modelo público não estatal, financiado por um fundo comunitário, por dotações do governo estadual, doações privadas, e complementado pela cobrança de matrículas. Esse modelo não é organizado em cátedras, mas em departamentos, com a ampla participação dos docentes. O poder está com o conselho de curadores (não acadêmico), que é responsável por toda a parte administrativa e financeira, pela escolha do reitor, pela definição das áreas de expansão, inclusive com relação à pesquisa. Segundo Durham, as universidades americanas

“(...) foram constituídas preservando os colleges como formação básica, que fornece o título de bacharel, e sobrepondo a eles as escolas de formação profissional (como de Medicina,
Direito, Engenharia e outras) e a escola graduada (que copiamos como pós-graduação), que forma mestres e doutores (Durham, 2005, p.11)”.

É interessante perceber que não há exigências com relação a um currículo mínimo ou exame de Estado para o ingresso no college ou na pósgraduação, o que permite à Universidade atender um público heterogêneo. O sistema de ensino superior americano é muito diversificado (escolas vocacionais, institutos tecnológicos, escolas de administração, etc.), o que cria condições para o atendimento massivo na educação superior. Segundo Durham (2005), cerca de $40 \%$ dos alunos estão em instituições do tipo college, e não em universidades. $\mathrm{O}$ college (bacharelado) não outorga credenciais profissionais, e a entrada nos cursos de pósbacharelado é muito competitiva. O pré-requisito para a entrada na pós-graduação (e aí está a maior barreira seletiva) é ter tido, ao longo do college, um desempenho escolar excelente.

No Brasil, diferentemente de outros países da América Latina, a criação de universidades foi tardia. Em 1920, o governo federal instituiu a Universidade do Rio de Janeiro, a partir da junção de escolas já existentes que, muito embora, continuaram a funcionar de forma isolada (Mendonça, 2000). Posteriormente, foram criadas outras universidades, a Universidade de São Paulo, em 1934, e a Universidade do Distrito Federal, em 1935, que importaram o modelo de cátedras e trouxeram professores do exterior. O Manifesto dos Pioneiros da Educação Nova, em 1932, lançou as bases da concepção de Universidade com tríplice função: pesquisa, docência e extensão, e enfatizou o lugar central da pesquisa. Esse documento critica as instituições de ensino superior existentes até então, cujos objetivos não iam além da formação profissional. (Mendonça, 2000; Chauí, 2006).

Cursar a Universidade passa a significar status para parcela da classe média brasileira a partir do final da década de 50. Aliada à aquisição de um conhecimento específico, está também a
É interessante perceber que não há exigências com relação a um currículo mínimo ou exame de Estado para o ingresso no college ou na pós-graduação, o que permite à Universidade atender um público heterogêneo. 
"(...) impedir a mercantilização do ensino superior, buscando criar mecanismos para garantir a qualidade e democratizar o acesso com políticas de inclusão social (...) e fortalecer o vínculo para a consolidação de um país democrático e inclusivo"

BRASIL, 2005 promessa de uma situação profissional bem remunerada e socialmente valorizada graças ao diploma de nível superior. Essa ambição, vivida num momento político de governo populista, tem, como resposta, a primeira expansão do ensino superior no País. Assistimos, ao longo do século $\mathrm{XX}$, ao sucateamento da escola pública de ensino fundamental, ao lado da manutenção de um exame vestibular com características fortemente seletivas para a Universidade, o que levou a que somente os alunos que tivessem oportunidade de cursar boas escolas conseguissem uma vaga na educação superior pública.

A partir da segunda metade da década de 1990, houve uma nova expansão do ensino superior, no Brasil, agora desordenado e com marcada ênfase no ensino privado, de modo que, atualmente, $70 \%$ das vagas se encontram nessa modalidade de ensino, contra apenas 30\% de vagas no ensino superior público (BRASIL, 2005). $\mathrm{O}$ aumento de vagas no ensino particular teve, como uma de suas conseqüências, o surgimento de uma nova situação, em que vários cursos passaram a oferecer mais vagas do que os candidatos neles inscritos. Assim, o processo seletivo, nessas instituições, passou a ser regulado pela existência ou não de vagas, com possibilidade de acesso de todos os alunos que tenham condições de arcar com as mensalidades cobradas.

Independentemente da necessidade de uma discussão mais aprofundada sobre as formas de admissão ao ensino superior, é fato que essa nova forma de entrada na faculdade tem inserido uma população maior e mais variada daquela que outrora a cursava. Nesse novo panorama de alunos, destacamos aqueles com deficiência intelectual e outras necessidades educacionais especiais relacionadas a dificuldades de aprendizagem, que têm ingressado legitimamente nesse espaço acadêmico.

Ao retomar a história, é possível notar que desde sua criação, na Europa medieval, as universidades têm mantido, como marca, a autonomia administrativa e didático-científica. Durham (2005) afirma que, ao longo de sua existência, a conquista da autonomia sempre se estabeleceu como resultado de uma negociação entre a Universidade e instâncias fora dela. Ora, diante da rápida e drástica alteração na quantidade e nos propósitos dos novos ingressantes no ensino superior, é tempo de surgirem novas negociações que possam abranger todo o ensino superior, não apenas à luz das determinações legais que sustentam a prática da inclusão em todos os níveis de ensino, mas também no questionamento da liberalização e da conseqüente mercantilização do ensino, muito presente na educação superior. Não se trata de menosprezar as medidas legais, pelo contrário, elas são necessárias para dar sustentação às ações educativas, porém as discussões devem ultrapassar esse âmbito e refletir-se no cotidiano das práticas dos educadores e dos educandos.

Dentro da esfera legal, as transformações, tanto na forma como nos objetivos do ensino superior, levaram à necessidade de uma nova reforma universitária, atualmente em curso no nosso país, e que tem, entre suas finalidades,

“ (...) impedir a mercantilização do ensino superior, buscando criar mecanismos para garantir a qualidade e democratizar o acesso com políticas de inclusão social (...) e fortalecer o vínculo para a consolidação de um país democrático e inclusivo"(BRASIL, 2005, p.1).

Essa afirmação evidencia a mudança operada nos objetivos educacionais, ao mesmo tempo em que aponta o problema da crescente pressão financeira presente nas instituições de ensino superior em nosso país. A preocupação em garantir que todos tenham acesso a essa modalidade de ensino também demonstra que o ensino superior de fato deixou de ser direcionado a uma elite e passa a constituir-se, mais e mais, em aspiração de grande parte da população brasileira, incluindo-se aí aqueles de baixa renda. 
Sob tal perspectiva, trata-se de um novo desafio para o ensino superior estabelecer seus objetivos e posicionar-se a respeito das condições e necessidades inerentes à formação pretendida em cada um de seus cursos. Atualmente, o acesso ao ensino superior de todos os que nele se inscrevem tem criado um mecanismo perverso de aceitação desse aluno por meio do processo seletivo que, ao mesmo tempo, acaba por barrar a sua permanência através de sucessivas retenções no curso escolhido. Tratase de uma inclusão marginal, como sugere Martins (1997), que faz contar em números positivos uma população que fica presa no 'limbo' do ensino superior particular sem, todavia, completar a sua formação.

Exposto o panorama do ensino superior, cabe discutir o posicionamento brasileiro em torno da educação inclusiva, a fim de articular as questões suscitadas pela inclusão de alunos com necessidades educacionais especiais no ensino superior.

\section{Histórico da educação inclusiva}

O Brasil fez opção pela construção de um sistema educacional inclusivo ao concordar com a Declaração Mundial de Educação para Todos na conferência mundial da UNESCO, em 1990. Ao se tornar signatário da Declaração de Salamanca (UNESCO, 1994), reafirmou esse compromisso, e deu visibilidade às questões relativas à inclusão e exclusão na educação. Desde então, instalouse um processo de profundas transformações no sistema educacional brasileiro, que teve, como desdobramento, mudanças na legislação e na elaboração de diretrizes nacionais para a educação, todas elas norteadas pela idéia da educação inclusiva. No entanto, embora a legislação tenha se adequado aos objetivos da educação inclusiva, a maior parte de nossos alunos permanece em ambientes de ensino segregado.

A concepção de educação inclusiva busca contemplar a atenção para as diferentes necessidades decorrentes de condições individuais (por exemplo, as deficiências), econômicas ou socioculturais dos alunos. $\mathrm{O}$ termo necessidades educacionais especiais (NEE) é freqüentemente utilizado nos documentos oficiais, e coloca ênfase nas ações que a escola deve promover para responder às diferentes necessidades dos alunos. Utilizaremos o termo deficiência para nos referir às questões específicas de alguns alunos, sem perder de vista que tal condição deve ser pensada no âmbito das necessidades educacionais especiais.

Diversas pesquisas têm evidenciado ser a educação inclusiva tão ou mais benéfica que a segregada para todos os alunos (Ainscow, Porter, Wang, 1997; Monteiro, Castro, 1997; Odom, Deklyen, Jenkins, 1984; Pastells, 1993; Sekkel, 2003). Essas pesquisas mostram que tanto os alunos com deficiências quanto os alunos normais ganham com essa convivência, e não há registros de quaisquer efeitos adversos com relação aos processos de aprendizagem ou de socialização. Tais efeitos, no entanto, são perceptíveis quando alunos deficientes são simplesmente matriculados e passam a freqüentar escolas regulares, sem que haja um ambiente que acolha e valorize as diferenças.

As transformações necessárias para a implementação de um sistema educacional inclusivo têm sido amplamente debatidas no cenário da educação infantil e do ensino fundamental. Temos, de um lado, posições como as de Ortega (1995), que defende o processo de inclusão "sem que se alterem os objetivos a serem atingidos pelos alunos, sem modificar, assim, o método ou mesmo o ritmo e a dinâmica das aulas, mas com a imposição de limites claros para a flexibilidade na instituição educacional”. De outra parte, há aqueles que vêem, a partir da questão da inclusão, a chance de modificar radicalmente a estrutura escolar como um todo e buscam questionar modelos e atitudes considerados ultrapassados no modo tradicional de ensino. Nessa visão, a entrada das crianças com deficiência ou com outras 
necessidades especiais na rede regular de ensino impõe a reflexão da prática e dos objetivos educacionais de toda a equipe escolar para todos os seus educandos. (Ainscow, Porter, Wang, 1997; Mantoan, 2003; Sekkel, 2003).

As transformações pelas quais a educação brasileira tem passado ainda suscitam muitas controvérsias. A presença do especialista, a elegibilidade do aluno nos diferentes níveis educacionais, a aplicação de provas especiais e a alteração do currículo, por exemplo, permanecem temas centrais do debate. A explicitação de cada uma das posições a respeito desses temas fugiria ao propósito deste artigo. O importante a ressaltar, neste momento, é que estamos imersos em um campo ainda em construção, que abriga posições divergentes a respeito dos caminhos a serem percorridos em direção a uma educação inclusiva.

Do ponto de vista do professor, a diversificação em seu método e na organização do currículo é bem aceita, segundo Gracia (2000), embora a preocupação e a rejeição, diante de alunos com deficiências, esteja presente, o que contribui

A presença do especialista, a elegibilidade do aluno nos diferentes níveis educacionais, a aplicação de provas especiais e a alteração do currículo, por exemplo,

permanecem temas centrais do debate. para sua conduta em sala de aula como um todo (Cook et al., 2000). Pesquisa realizada com futuros professores aponta que eles mantêm uma postura favorável à educação inclusiva quando esta é apresentada de modo genérico, porém, níveis maiores de rejeição a essa modalidade de educação surgem conforme se apresentam situações relativas ao ritmo de aprendizagem e à interação entre os alunos (Crochík et al., 2006). Essas constatações reforçam a necessidade, já apontada por León (1994) e Mittler (2003), de que a formação dos futuros professores seja voltada para a educação inclusiva, uma vez que a atitude do professor é crucial na superação das barreiras à inclusão em sala de aula. Como foi possível notar, pesquisas e discussões sobre os efeitos, nos alunos e nos professores, dessa modalidade de educação têm sido realizadas visando a buscar os pontos mais frágeis a serem trabalhados na educação bem como avaliar os avanços que a educação inclusiva tem trazido.

\section{A inclusão e o ensino superior}

Conforme os níveis de escolarização se elevam, as discussões e as práticas educacionais voltadas à inclusão se tornam escassas, e, quando ocorrem, o tema da educação inclusiva volta-se para a questão da inclusão social das camadas mais pobres da população ou para as ações afirmativas, como as cotas para estudantes negros ou afro-descendentes (Silva, 2006; Moehlecke, 2004). Somem de cena os estudantes com deficiência e outras necessidades educacionais especiais. Pobres e negros são alvos do preconceito em nossa sociedade, e, desse ponto de vista, tais ações são bem-vindas, pois podem contribuir efetivamente para a mudança social no sentido da construção de uma sociedade menos discriminatória. É importante, no entanto, não deixar de dar visibilidade aos outros alvos de preconceito e exclusão no nosso país.

O preconceito é um assunto imprescindível de ser considerado ao abordar o tema da educação inclusiva. As políticas, informações e orientações não são suficientes para a mudança de atitude dos educadores e dos alunos frente às minorias, seus alvos potenciais. O preconceito é uma defesa que impede a experiência e se interpõe no relacionamento, além de produzir uma falsa generalização que rejeita argumentos vindos do contato com a realidade externa (Adorno, Horkheimer, 1985; Crochík, 1997). Se entendermos o preconceito como manifestação individual cuja origem é social, podemos antever sua presença nas relações em sala de aula. Isso torna necessário um trabalho de conscientização dessas determinações presentes nas relações e de reflexão sobre as possíveis ações para sua superação. Tal trabalho deve ser iniciado na formação do professor, o que reforça a necessidade de formação pedagógica do docente do ensino superior que contemple a reflexão sobre as atitudes frente às diferenças. Essa reflexão revela-se tão importante quanto o domínio de conteúdos específicos das áreas de conhecimento, pois ambos os fatores podem ser decisivos para a efetividade das ações educativas. 
Ainda é escassa a produção de pesquisas bem como a implantação de políticas para a inclusão de pessoas com deficiência no ensino superior. Em 2006, a Secretaria de Educação Superior, do Ministério da Educação, recebeu 17 milhões em investimentos voltados à inclusão de índios, negros e pessoas com necessidades educacionais especiais. É interessante notar, todavia que, desse total, apenas 1,5 milhão - menos de $10 \%$ dos investimentos - foram destinados a programas de acesso e permanência no ensino superior das pessoas com tais necessidades (BRASIL, 2006).

Algumas iniciativas isoladas buscam subsidiar a ação dos professores e incentivar a permanência dos alunos com necessidades educacionais especiais nos cursos superiores. Por exemplo, em 2005, o Programa USP Legal divulgou a Orientação aos docentes sobre alunos com deficiência, com o objetivo de subsidiar as ações dos professores e da comunidade universitária com relação às necessidades dos alunos com deficiências físicas e sensoriais. Tais programas se revelam necessários para fornecer subsídios e legitimar novas práticas educacionais. Não se trata de integrar ou adaptar as pessoas com deficiência ao status quo. Ao contrário, são os objetivos do ensino superior, bem como seus modos de avaliação e currículo, que necessitam de uma reformulação frente a esse novo desafio. Assim como nos demais níveis de ensino, tratase de assumir o debate proposto a partir da inclusão, para repensar modelos e objetivos educacionais também no ensino superior e encarar as questões da flexibilização do currículo, da necessidade ou não do especialista, da aplicação das provas especiais como forma alternativa de avaliação, enfim, as questões que se impõem já há mais de uma década na educação brasileira. Como mencionado anteriormente, os alunos marginalmente incluídos tornam-se dados estatísticos de ingresso, mas permanecem desprovidos de atenção mesmo diante de sucessivas retenções nas disciplinas.
O ingresso de alunos com necessidades educacionais especiais nos cursos superiores muitas vezes não se dá de modo explícito. As dificuldades podem se revelar para a classe e para os professores paulatinamente. Há casos em que o próprio aluno desconhece sua condição ou não tem consciência das suas dificuldades, como o de uma aluna que se descobriu portadora de dislexia a partir dos conteúdos estudados nas aulas de neurociências. Algumas necessidades educacionais especiais podem passar despercebidas pelo professor nos trabalhos em pequenos grupos, principalmente nas produções de texto coletivas, e pode mesmo ocorrer que, apenas na avaliação final, o professor se depare com as dificuldades específicas daquele aluno. Entram em cena aqui as especificidades das disciplinas e dos métodos utilizados pelos diferentes professores.

Freqüentemente, os alunos são os primeiros a perceber as dificuldades do companheiro de sala. Numa determinada ocasião, uma aluna com deficiência intelectual passou a ser rejeitada pelos colegas pelo estranhamento que seu comportamento provocava. Posteriormente, ficou explicitado, pelos alunos, o temor de serem prejudicados nos trabalhos coletivos pelo baixo rendimento da colega. O receio de que a presença de alunos com deficiência possa diminuir o rendimento escolar da turma é muito presente no imaginário de pais e professores na educação básica, e percebe-se, pelo exemplo citado, a tendência a que se reproduza na educação superior. Tal questão nos remete novamente ao preconceito e à necessidade da formação de professores capazes de lidar com tais diferenças para impedir que o medo domine as relações.

Amaral (1995) chama a atenção para o medo da "contaminação” pelo convívio, que denomina “contágio osmótico”, que leva a uma leitura tendenciosa da deficiência. É importante entender a presença do medo subjacente a essa manifestação, porque de nada vai adiantar 
A educação

inclusiva pressupõe

a participação

coletiva na

decisão das

questões da sala

de aula e da

instituição escolar

bem como a

necessária

flexibilidade na

utilização dos

recursos

institucionais,

humanose

materiais. contrapor uma argumentação racional na tentativa de deixar evidente a suposição infundada, pois o medo originado pelo sentimento de ameaça criaria a necessidade de buscar outras racionalizações. É o medo que tem que vir à consciência, e esse é um desafio que dificilmente poderá ser realizado de forma isolada. Sekkel (2003) aponta a necessidade de um ambiente inclusivo fundado no compromisso com os valores humanos e articulado coletivamente, em que o professor possa expor os seus receios, limites e necessidades. O professor precisa ser incluído, pois, sem essa possibilidade, ele permanecerá isolado na escola, e lançará mão de atitudes defensivas para se proteger de ameaças, reais e imaginárias. A publicação Educação Inclusiva: experiências educacionais inclusivas (BRASIL, 2007) apresenta outra possibilidade para a necessidade de compartilhamento de experiências, criando oportunidades de troca a partir das diferentes realidades presentes no território nacional.

A educação inclusiva pressupõe a participação coletiva na decisão das questões da sala de aula e da instituição escolar bem como a necessária flexibilidade na utilização dos recursos institucionais, humanos e materiais. A possibilidade de o professor poder contar com o apoio dos colegas e de outros profissionais, de repensar a estratégia de aula, de rever o plano de ensino e de contar com a participação dos alunos e sua contribuição na resolução das questões específicas que se apresentarem é de importância fundamental numa proposta educacional voltada para a inclusão. Mesmo considerando a especificidade das disciplinas, pode-se partir do pressuposto que todos os professores necessitam de um apoio institucional para realizar tais flexibilizações e mudanças, e, nesse sentido, é fundamental que os objetivos ligados a cada curso nas IES estejam claros a todos aqueles que participam do seu desenvolvimento.

É com base nesses objetivos que a elegibilidade dos alunos para os cursos pode ser definida.
Numa experiência recente, a presença de uma aluna com deficiência intelectual num curso superior gerou discordâncias entre os professores, que, equivocadamente, tomaram a seu cargo a decisão sobre a pertinência da permanência ou não da aluna no curso. Deveriam ser adotados conteúdos e critérios de avaliação diferenciados para tal aluna? Qual aspecto deveria ser preponderante na avaliação: a aquisição de conhecimentos técnicos específicos para uma futura atuação profissional ou o desenvolvimento humano? Tal discussão não deve recair sobre os ombros do professor, mas deve ser tomada pela instituição, de forma participativa. Sua ocorrência evidencia o perverso mecanismo do ensino superior brasileiro, que tem o explícito interesse em aumentar o ingresso de clientes em seus bancos escolares, mas não se atém em discutir, com o corpo docente, os objetivos e limites de suas atribuições.

Se atentarmos para o histórico das universidades e seus desdobramentos em nosso país, perceberemos que seu ensino, tradicionalmente, é voltado para as elites econômicas e intelectuais, o que marca o espaço acadêmico como um lugar destinado aos privilegiados. A expansão do ensino, dentro dessa perspectiva, deve ser vista com atenção, a fim de que o discurso da democratização do acesso não se transforme apenas em mais uma bandeira das políticas públicas que, travestida de novidade, termina por manter, na prática, a elitização de modo ainda mais perverso através inclusão marginal anteriormente apontada. A correção política do discurso em favor das minorias, aliada à lógica neoliberal presente no ensino superior brasileiro, não necessariamente trabalha em favor do sucesso escolar de todos aqueles que ingressam numa faculdade. (Viegas, Angelucci, 2006).

Ao ampliar o número de alunos matriculados, muitas vezes, o que temos é também a ampliação do fracasso escolar, através de sucessivas retenções ou do abandono do curso superior. A omissão institucional com relação à 
explicitação de objetivos e elegibilidade do seu alunado leva a que os limites não definidos se tornem questões concretas na sala de aula. É por esse motivo que o professor equivocadamente, como já foi enfatizado - é levado a tratar o aluno com necessidades educacionais especiais no âmbito da relação individualizada, o que coloca ambos numa situação fragilizada, sem amparo para a tomada de decisões. É importante considerar que, se o ingresso de tal aluno foi legitimado pelo exame vestibular ou processo seletivo, ele tem o direito de encontrar condições de permanência e conclusão do curso que levem em consideração as suas dificuldades.

Além das questões mais visíveis presentes na avaliação, temos também as dificuldades dos professores, quando estes têm, em sua classe, um aluno com deficiência. Nos outros níveis de ensino, temos pesquisas que apontam o fato de que a atitude do professor é de suma importância para a permanência no processo escolar e para a integração do aluno com deficiência com os demais alunos (León, 1994; Ortega, 1995, e Mittler, 2003). Nem sempre, no entanto, o professor tem uma predisposição favorável ao trabalho com alunos deficientes.

Alguns professores assumem uma postura protetora e paternalista diante dos alunos com necessidades educacionais especiais; outros podem se aproximar e conhecer melhor suas limitações, enquanto outros ainda as ignoram. Quanto ao paternalismo, Amaral (1995) destaca que o preconceito nem sempre ocorre através de uma valorização negativa de seu alvo. A superproteção é um bom exemplo de que podemos agir de forma a proteger e até valorizar positivamente o esforço de alguém com deficiência, mas tal proteção revela a nossa certeza na incapacidade daquela pessoa em realizar as ações propostas, o que nos leva a fazer pelo outro antes que ele possa experimentar suas possibilidades. Ainda caminhando com Amaral (op. cit.), devemos ter a clareza de que é impossível ficar indiferente diante da deficiência. Segundo a autora, as emoções se intensificam diante desse tipo de contato, sobrepondo-se ao entendimento racional da situação. $\mathrm{O}$ ataque e a fuga seriam reações emocionais que funcionam como opostos da mesma moeda: o medo, que impede o contato com a pessoa.

Nesse sentido, tanto o comportamento do professor que ignora os alunos com necessidades educacionais especiais quanto o daquele que se coloca contra a permanência deles em sala de aula (a fuga e o ataque) podem resultar do sentimento de ameaça que não encontra continente na instituição. Para que a educação inclusiva possa avançar, é de fundamental importância que a atitude de todos os que participam do processo educacional possa encontrar espaço de acolhimento e transformação. A abertura à experiência, como propõe Adorno (1995), é essencial nesse processo, e ela só é possível se o medo subjacente às nossas atitudes puder se tornar consciente. É nesse sentido que o autor identifica a educação para a emancipação com a educação para a experiência, numa sociedade em que a frieza nas relações humanas se tornou universal.

\section{Tecendo algumas considerações finais}

A presença de pessoas com necessidades educacionais especiais no ensino superior é um novo desafio. O processo de construção de um espaço inclusivo na educação, qualquer que seja seu o nível, não se dá por meio de uma padronização; ao contrário, é necessário que a inclusão se faça a partir da experiência e do reconhecimento das diferenças. A participação de pessoas com deficiência em sala de aula pode ser uma contribuição para todos os alunos, ao promover a reflexão sobre as práticas educacionais a partir das questões suscitadas no cotidiano da sala de aula, o que leva à flexibilização e à reinvenção das mesmas (Ainscow, Porter, Wang, 1997; Sekkel, 2003, 2005). 
A questão da certificação para o exercício profissional se coloca como central para a tomada de decisão com relação à elegibilidade do alunado dos cursos. Pode um aluno cego se tornar um cirurgião? Talvez não, mas isso não o impede de ser médico. E um aluno com déficit cognitivo, quais os limites para o seu exercício profissional? A elegibilidade através do mérito, num vestibular competitivo, elimina essa questão, já que o aluno com déficit cognitivo não terá condições de ultrapassar essa barreira. Mas quando se coloca o objetivo de democratização do acesso ao ensino superior e a ampliação do número de vagas, tais fatos fazem com que a competição não seja mais um impedimento e que essas questões tenham que ser pensadas com cuidado e respeito por todos os envolvidos.

A partir dos pontos levantados nos diversos âmbitos abordados, daremos ênfase a três desafios aqui identificados, que abrangem três níveis de ação: o institucional, a formação de professores e o cotidiano escolar. Em primeiro lugar, o desafio das instituições de ensino superior diante da necessidade de assumir posições a respeito da elegibilidade dos alunos aos cursos oferecidos. No caso das universidades, deve manter-se presente a autonomia que lhe é característica como instituição social frente às demandas sociais de inclusão (Chauí, 2006). Vimos que as IES têm sofrido mudanças significativas desde o seu surgimento até os dias atuais ao acompanhar as demandas sociais em diferentes momentos históricos. Seu posicionamento frente aos desafios da educação inclusiva é fundamental. Sem essa definição, alunos e professores são colocados em situações constrangedoras e inaceitáveis, como já vem acontecendo.

O segundo desafio refere-se à formação de professores. Qualquer que seja o nível de ensino, é de fundamental importância a educação para as diferenças. Aqui o foco recai sobre as licenciaturas e toda a educação básica, além das necessidades específicas de formação docente no ensino superior. Também é importante ressaltar, acerca das licenciaturas e de seus efeitos na educação básica, a necessidade de educar para as diferenças, tanto em relação ao outro quanto no que diz respeito à compreensão e aceitação da própria condição e seu desvio de um tipo ideal, durante todo o processo escolar. Além disso, a questão apontada anteriormente, de que a formação docente não tem sido considerada uma exigência no ensino superior, precisa ser revista diante dos desafios da educação inclusiva. A competência técnica não garante a condição de reconhecer e trabalhar com as diferenças em direção à emancipação, e não podemos perder de vista que todo conhecimento deve servir às finalidades humanas. (Adorno, 1995).

O terceiro desafio diz respeito à competência do educador em identificar, acolher e trabalhar com as diferenças em suas salas de aula. Nomear, perguntar, investigar com os alunos em questão e com a classe as especificidades a serem levadas em conta no processo educacional são ações importantes. A abordagem individual, restrita à relação particular entre o professor e o aluno com necessidades especiais, não é suficiente, pois a educação escolar é uma situação eminentemente grupal. É fundamental que todos os protagonistas das ações educacionais (professores, alunos, coordenadores e diretores) reconheçam e legitimem as diferenças presentes em sala de aula e participem da construção de condições efetivas de ensino e aprendizagem.

A reforma universitária atualmente em curso deve levar em conta essas questões, tendo em vista que a Universidade possui limites, mas deve, ao mesmo tempo, preencher as demandas sociais de inclusão. 
Marian A. L. Dias Ferrari - Doutora em Psicologia pelo IP-USP, docente do Curso de Psicologia da Universidade Presbiteriana Mackenzie e membro do Laboratório de Estudos do Preconceito - LaEP - do Instituto de Psicologia da Universidade de São Paulo.

Marie Claire Sekkel - Doutora em Psicologia pelo IP-USP, docente do Instituto de Psicologia da Universidade de São Paulo e coordenadora do Laboratório de Estudos do Preconceito - LaEP - do Instituto de Psicologia da Universidade de São Paulo.

Instituto da Psicologia : Av. Prof. Melo Morais, 1721 - Bloco A CEP: 05508-900 São Paulo-SP E-mail:sekkel@usp.br

ADORNO, T. W. Educação e Emancipação. Rio de Janeiro: Paz e Terra, 1995.

ADORNO, T. W; HORKHEIMER, M. Dialética do Esclarecimento. $2^{\mathrm{a}}$ ed. Rio de Janeiro: Jorge Zahar Editor, 1969, 1985.

AINSCOW, M.; PORTER, G.; WANG, M. Caminhos para as Escolas Inclusivas. Lisboa: Instituto de Inovação Educacional, 1997.

AMARAL, L. A. Conhecendo a Deficiência: em Companhia de Hércules. São Paulo: Robe, 1995.

Diferenças, Estigma e Preconceito: o Desafio da Inclusão. In: Oliveira, M. K., Souza, D. T.; Rego, T. C. (org.), Psicologia, Educação e as Temáticas da Vida Contemporânea. São Paulo: Moderna, 2002, pp. 233-268.

BRASIL. Ministério da Educação. Reforma universitária. Disponível em http://www.mec.gov.br/reforma/feito.asp. Acesso em 17 jul. 2005.

BRASIL. Secretaria de Educação Superior. Subsecretaria de Comunicação Institucional da Secretaria-Geral da Presidência da República. Inclusão no ensino superior recebeu investimentos de R\$ 17 milhões. Em Questão. Disponível em < http://www.mec.gov.br/ sesu/emquestao393/html>. Acesso em 22 fev. 2006.

BRASIL. Ministério da Educação. Secretaria de Educação Especial. Educação Inclusiva: experiências educacionais inclusivas 2006. Disponível em http://portal.mec.gov.br/seesp/arquivos/pdf/ experiencias\%20inclusivas.pdf. Acesso em 12 fev. 2007.

CHAUÍ, M. A universidade pública sob nova perspectiva Disponível em http://www.anped.org.br/reunioes/26/inicio.htm. Acesso em 10 jul. 2006

COOK,B.G;TANKERSLEY,M.COOK, L.; LANDRUN,T.J.Teacher's attitudes toward their included students with disabilities. Exceptional Children, Glasgow, v. 67, n. 1, pp.115-135, 2000.

CROCHÍK, J.L.;FERRARI, M.A.L.D.; HRYNIEWICZ, R. R.; BARROS,O N.; NASCIMENTO, R.B. Preconceito e atitudes em relação à educação inclusiva. PsicologiaArgumento, Curitiba, v. 24, n. 46, pp. 55-70, jul/ set. 2006.

Robe, 1997.

. Preconceito, indivíduo e cultura. São Paulo:

DURHAM, E. R. A autonomia universitária - extensão e limites. Disponível em <http://www.usp.br/iea/ensinosuperior/ confdurham.html>. Acesso em 29 abr. 2005.

JENKINS, J. R.; ODOM, S. L.; SPELTZ, M.L. Effects of social integration on preschool children with handicap. Exceptional Children, Glasgow, v. 55, n. 5, pp. 420-428, 1989.

GRACIA, V. S. La Educación Integradora en Europa. Valencia: Artes Gráficas Soler, 2000.
LEÓN, M.J. La perspectiva del profesor tutor sobre los problemas de la integración de los niños con necesidades educativas especiales. Revista de Educación Especial, Barcelona, n. 14, pp.77-83, ago./ 1994.

MANTOAN, M. T. E. Inclusão Escolar: o que É? Por quê? Como Fazer? São Paulo: Moderna, 2003.

MARTINS, J. S. A Exclusão Social e a Nova Desigualdade. São Paulo: Paulus, 1997.

MENDONÇA, A. W. A Universidade no Brasil. Revista Brasileira de Educação, Rio de Janeiro, n.14, pp.131-150 maio/ago. 2000

MITTLER, P. Educação Inclusiva: Contextos Sociais. Porto Alegre: Artmed, 2003.

MOEHLECKE, S. Fronteiras da Igualdade no Ensino Superior: Excelência e Justiça Racial. Tese de doutorado em Educação. Universidade de São Paulo, São Paulo, 2004.

MONTEIRO, M. B.; CASTRO, P. Cada Cabeça sua Sentença. Oeira: Celta Editora, 1997.

ODOM, S. L.; DEKLYEN, M.; JENKINS, J. R. Integrating handicapped and nonhandicapped preschoolers: developmental impact on nonhandicapped children. Exceptional Children, Glasgow, v. 51, n. 1, pp.41-48, 1984.

ORTEGA, C. J. Educación, compensación y diversidad. Revista de Educación Especial, Barcelona, n. 20, pp.9-15, jul./set. 1995.

PASTELLS, A. A. La integración de alumnos deficientes en la escuela ordinaria. Revista de Educación Especial, Barcelona, n. 12, pp.4457, ago./ 1993.

SEKKEL, M. C. A Construção de um Ambiente Inclusivo na Educação Infantil: Relato e Reflexão sobre uma Experiência. Tese de doutorado em Psicologia. Universidade de São Paulo, São Paulo, 2003.

. Reflexões sobre possibilidades e limites da educação inclusiva. Boletim de Psicologia, São Paulo, v.LV, n. 122, pp.43-58, 2005.

SILVA, S. Diversidade e exclusão: a sensibilidade de quem as vive. Construindo alternativas de política de inclusão. Disponível em http://www.anped.org.br/reunioes/26/inicio.htm. Acesso em 10 jul. 2006.

UNESCO. Declaração de Salamanca e linha de ação sobre necessidades educativas especiais. Brasília: CORDE, 1994.

VIEGAS, L.S.; ANGELUCCI, C.B. (orgs.) Políticas Públicas em Educação: uma Análise Crítica a Partir da Psicologia Escolar. São Paulo: Casa do Psicólogo, 2006.

\section{Referências}

